\title{
Why Folkbiology Matters: Resource Conflict Despite Shared Goals and Knowledge
}

\author{
Douglas Medin $\cdot$ Norbert Ross $\cdot$ Douglas Cox $\cdot$ Scott Atran
}

Published online: 22 December 2006

(C) Springer Science + Business Media, LLC 2006

\begin{abstract}
There is a continuing controversy over Native American fishing and hunting rights. We show that Native American (Menominee) and European American fish experts have a common knowledge base and share values and attitudes associated with fishing practices (though organized around different ethical principles). Nonetheless, perceived group differences are dramatic (especially European American perceptions of Native Americans). Cultural differences in models of nature and associated inference processes appear to mediate these stereotypes and may hold the key to reducing intergroup conflict over resources.
\end{abstract}

Key words Folkbiology · inductive reasoning .

cultural conflict $\cdot$ resource distribution $\cdot$ Menominee

D. Medin $(\bowtie)$

Department of Psychology, Northwestern University, 2029 Sheridan Road,

Evanston, IL 60208, USA

e-mail: medin@northwestern.edu

N. Ross

Vanderbilt University,

Nashville, TN, USA

D. Cox

Hilary Waukau Environmental Services Center,

Keshena, WI, USA

S. Atran

University of Michigan,

Ann Arbor, MI, USA

S. Atran

CNRS,

Paris, France
From a Menominee elder in Wisconsin: "One day when I was a little boy I made a slingshot. My mother told me to be careful with it and not to kill any animals. But it was a good slingshot and I couldn't keep myself from aiming at birds. My mother looked out the window and saw me just as I had my first success - killing a robin. She called to me and told me to bring the robin inside. Then she plucked its feathers, dressed it, and put it into a soup she was making. We ate it and it didn't taste bad. I learned that we're not supposed to waste anything."

From a European American fisherman who lives in the same area of Wisconsin and practices catch and release almost exclusively: "If you put the fish you catch into your holding tank, you can't expect them to be there when you come back to that spot to fish again."

\section{Introduction}

This paper is concerned with cultural differences in conceptions of nature and strategies for resource conservation. Management of common resources increasingly brings together individuals from different ethnic and cultural backgrounds. At times these cross-cultural encounters are advantageous, as differences in knowledge lead to advancement of perspectives on the resources in question. Although cross-cultural learning is more commonplace than often assumed (ethnic foods, etc.), it may represent an exception when it comes to resource management. Here, misunderstandings, resentment, and at times open conflict over resources are common (e.g., Chiarappa and Szylvian, 2003). Native American fishing rights in the Midwest and 
elsewhere seem to be a case in point. Renewal of gaming compacts for tribal casinos is frequently the occasion for state governments to pressure tribes to give up their treaty-based hunting and fishing rights (Tracy, 1998, "Tribal Claims Were Too Much," 1999). In the words of a Wisconsin state legislator, "the tribes should determine what is more important to them-fish or chips" ("Petition Seeks to Separate Spearfishing, Gaming," 1997). In the Midwest, particular attention and controversy has focused on Native American spearfishing rights (Nesper, 2002). For example, in Wisconsin sportsmen note that the allowable limit for walleye - perhaps the most prized fish to eat - is substantially lower (typically three rather than the normal five) on lakes where Native Americans spear ("Petition Seeks to Separate Spearfishing, Gaming," 1997; Wisconsin Department of Natural Resources, 2002). These observations can lead to the conclusion that tribes are threatening fish populations (Graunke, 2003). Native Americans, by contrast, may find it difficult to endorse fishing solely as entertainment. Exclusively practicing catch and release can be seen as disrespectful of fish in particular and nature in general.

Such observations suggest differences with respect to the value systems (fishing as a sport versus fishing for food) and the perceived impact each group's activity has on the environment. Recent findings from studies of folkbiological knowledge suggest cultural differences in knowledge and/ or values drive some of these disparities in behavior (see Atran et al., 1999; Ross, 2002). In related work in the tropical rainforest of Petén, Guatemala, we find different cultural models going hand in hand with respective differences in environmental values and practices (Atran et al., 2002). Even here, however, perceived group differences did not match reality. Prior to our study, native Itza' Maya generally described Q'eqchi' Maya as producing less damage to the forest than Ladino (Spanish speaking) immigrants, contrary to the fact. Our research shows that Ladino migrants but not Q'eqchi' Maya have acquired substantial knowledge of environmental practices from the native Itza' Maya, and have translated that knowledge into better practices. In short, intergroup perceptions can vary substantially from reality.

In this paper we present data on cultural models of Menominee Native American Indians and majority culture (European American) fishermen of central Wisconsin. In an initial step we studied cultural models of fish and fishing among expert Native American and European American fishermen (Medin et al., 2002; Medin et al., 2006). Standard sorting techniques and other probes were used to explore each group's categorization of local fish species, and perceived ecological relationships (fish-fish interactions). A second set of studies reported here targeted the values and goals of each population, as well as perceived group differences. The data suggest that both groups of experts share a knowledge base concerning the environment of local freshwater fish, though that knowledge is organized differently across the groups. In addition, the two groups generally share values and goals with respect to fishing. The key, surprising finding is that perceived group differences swamp actual differences, especially in the case of European Americans' perceptions of Menominees. We begin with some background information and then turn to a summary of our findings on knowledge organization and values and practices.

\section{Background}

The participants of primary interest for the present studies were (nonprofessional) experts in freshwater fish and fishing in north central Wisconsin. The experts were drawn from two populations, a Native American group (Menominee Indians) and a nearby majority culture (European American) group. Members of both groups engage in similar fishing activities, including fishing both rivers and lakes in all seasons and using live bait, flies (that they frequently tie themselves) and artificial lures. In the following paragraphs we describe these populations in a little more detail.

The Menominee ("Wild Rice People") are the oldest continuous residents of Wisconsin. Historically, their lands covered much of Wisconsin but were reduced, treaty by treaty, until the present 95,000 hectares was reached in 1856. Despite economic incentives to the contrary, the Menominee have preserved diversity and habitat types of their forest, which is managed by a tribal corporation. Overall, sustainable coexistence with nature is a strong value among the members of this population (Hall and Pecore, 1995). There are 4,000-5,000 Menominee living on tribal lands in three small communities.

The reservation has a number of lakes, ponds, creeks, and rivers. One of the major rivers is the Wolf River, which runs through the reservation into the town of Shawano and continues to Lake Winnebago. Shawano lies about $10 \mathrm{k}$ south of the reservation. Historically, lake sturgeon migrated up the river in the spring to spawn within the reservation, in the site shown in (Fig. 1). For a long time sturgeon provided an important food source for the Menominee. Early in the twentieth century, however, a dam was built south of the reservation, preventing the sturgeon from migrating up to the Menominee reservation. Recently the tribe has begun a program reintroducing sturgeon into reservation waters.

The tribe sets its own fishing regulations, which allow spear-fishing of some game fish (in contrast to Wisconsin state law which, with some exceptions, prohibits spearfishing), although only a minority of Menominee fishermen spearfish. The tribe sets limits on the numbers of different 


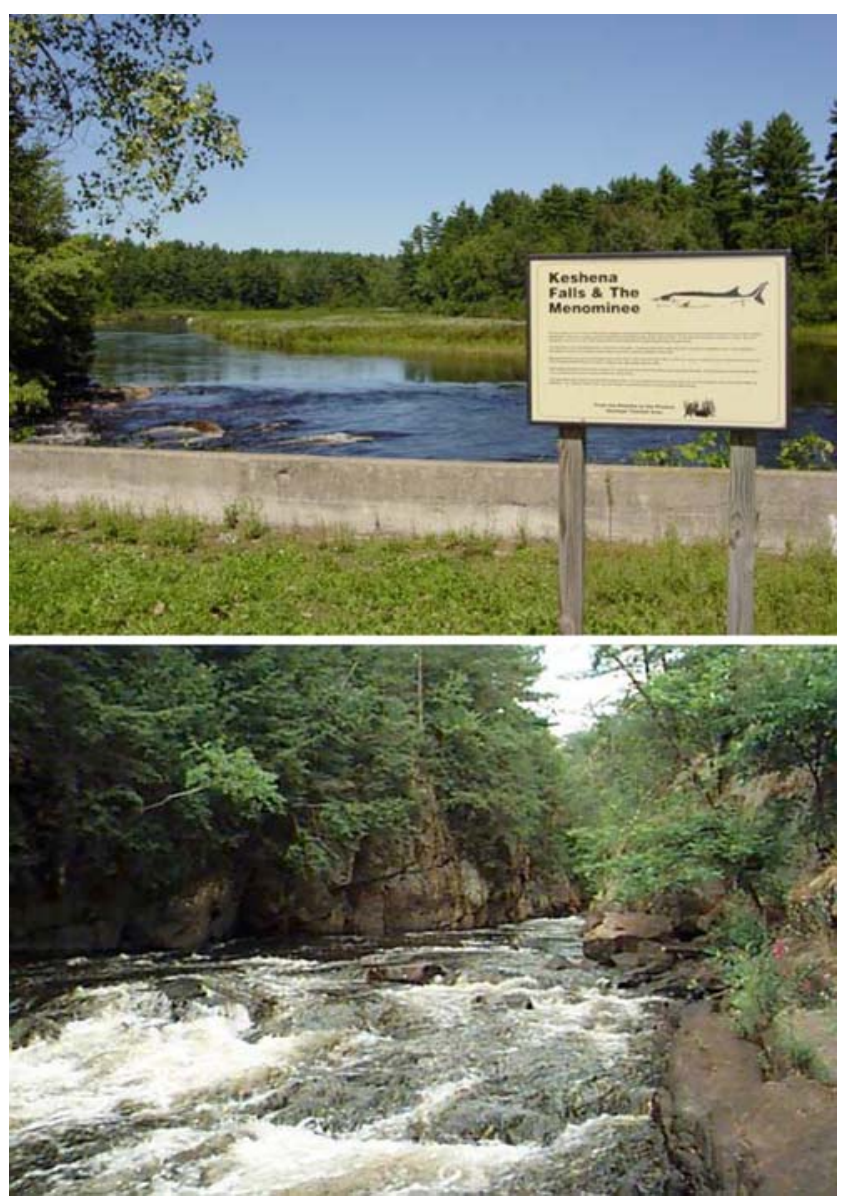

Fig. 1 Keshena Falls on the Menominee reservation. Prior to the construction of dams south of the reservation sturgeon would swim up to keshena Falls to spawn each spring.

gamefish that may be taken. ${ }^{1}$ Notably, tribal fishing regulations prohibit the "wanton destruction" of any fish. For Menominee, a strong cultural value is respect for nature and the belief that one should only take what is needed from the environment. Recent surveys reveal that the fish population on the reservation shows above average health and abundance (Schmidt, 1995). Fish are stocked in only a minority of the reservation lakes. There is some evidence that fish stocking may reduce biodiversity (e.g., Radomski and Goeman, 1995).

Just south of the reservation is Shawano County, the other focal area for our study. The major sources of income in the town of Shawano are light manufacturing, smallscale farming, and tourist recreation, mainly hunting,

\footnotetext{
${ }^{1}$ Setting specific limits is not necessarily compatible with the tradition of taking only what one needs. According to one member of the tribal conservation commission, "We have limits on the number of trout and other fish you can take each day. About $20 \%$ of the people accept and follow them. The other $80 \%$ say it's the white man's way and that one should take what one needs and not waste. They say, 'In the old days if you needed four trout for a nice meal you caught four. Now with the limit at ten people may take ten when they only need four."'
}

fishing, boating, jet-skiing, and snowmobiling. Shawano Lake is a major attraction and there are also several smaller lakes in the county. The Wolf River is connected by a channel to Shawano Lake.

Outdoor recreation is very important to many of the Shawano residents and many have fished since they were children. Several fishing clubs (e.g., a "Muskie Club") provide a social dimension to fishing. These clubs also raise money to stock lakes and rivers with desired fish and encourage the practice of "catch and release" (for example the Muskie club rules state that you will be expelled if you cause the death of a single muskie). There are usually several local fishing contests each year, open to Shawano residents, tourists, and professional fishermen. Prize money is considerable; for example, one of our informants had won $\$ 25,000$ in a muskie contest. (There are some small-scale fishing contests on one of the reservation lakes but the prizes are tiny by comparison and it is more a local, social event.)

\section{Knowledge Organization}

In a first step we studied cultural models of fish and fishing among expert Native American and European American fishermen (Medin et al., 2002; Medin et al., in press). We identified experts based on peer nominations and using a snowball method. We later confirmed expertise by probing for familiarity with 46 species of local fish (see Medin et al., 2002). Participants of the two groups did not differ with respect to age (mean: 44.8 years for European American experts and 48.8 for Menominee experts, range from 30 to 74 years), fishing experience (mean: 37.5 years for European American experts and 44 years for Menominee experts), or education (one mode at finishing high school and another at two years of college for both groups). None of our informants had any formal training in ichthyology and all informants had experience fishing streams, rivers, ponds, and lakes in all seasons. The participants in the different experiments overlapped extensively and for none of the tasks do any of the features mentioned differ significantly across groups. Therefore we do not make further mention of these attributes in the descriptions of the individual experiments.

\section{Measuring Agreement}

To assess responses within and across groups we applied the Cultural Consensus Model (CCM), as developed by (Romney et al. 1986; see also Atran et al., 1999, 2002). The CCM is a factor-analytic method for computing levels of agreement and disagreement in the structure and distribution of information within and across populations. The model assumes widely-shared information is reflected in a high concordance, or "cultural consensus," among 
individuals. Principal-components analysis is used to determine if a single underlying model holds for all informants from a given population: a strong group consensus exists if (1) the ratio of the latent root of the first to the second factor is high, (2) the first eigenvalue accounts for a large portion of the variance, and (3) all individual first factor scores are positive and relatively high. If this is the case, then the structure of the agreement can be explained by a single factor solution, the "consensual model." In this case, first factor scores represent the agreement of an individual with this consensual model.

Less formally, an overall consensus will emerge when there is a modest to strong positive correlation (agreement) of each informant's responses with those of every other informant. An overall consensus will fail when there are differences in knowledge or beliefs that may create subgroups with contrasting beliefs. For example, different political parties in the USA are associated with different opinions about social policy issues and one would not expect to find an overall consensus (with respect to these issues) no matter how large the sample size.

The CCM is also useful for analyzing within- and acrossgroup differences. These differences can be explored by (1) comparing first and second factor scores of each individual, and (2) analyzing patterns of residual agreement. Residual agreement is calculated by subtracting predicted agreement (equal to the product of first factor scores) from the observed agreement (Boster, 1987; Lopez et al., 1997). To the extent that within-group residual agreement is larger than acrossgroup residual agreement, one has evidence of reliable group differences. As we will see, within the same study one can obtain both an overall consensus and reliable between- and/or within-group differences. This situation will arise where general agreement for most of the probes is coupled with disagreement on a minority of the probes.

The CCM also functions as a cautionary device for crossgroup comparisons. A reliable cross-group difference in the absence of a within-group consensus suggests that withingroup variation may be at least as important as the crossgroup difference. Finally, the CCM can be used to determine the sample size needed to establish a consensus. Where within-group agreement is high, as few as $8-10$ informants may be needed. In the studies we report our sample size ranged between 14 and 17 per group. Although this does not seem like a large number, in almost all cases it is sufficient to establish a clear consensus where one exists. ${ }^{2}$ As a practical

\footnotetext{
${ }^{2}$ A small sample may also be sufficient to establish the absence of a consensus, which typically would take the form of one or more participants having a zero or negative loading on the first factor. Larger sample sizes are needed for cases where one is attempting to estimate population parameters or for estimating the relative frequency of different subgroups where there are within-group differences.
}

matter this also means that we will tend to focus on larger effects.

\section{Category Organization}

Standard sorting techniques and other probes were used to explore each group's categorization of local fish species. On a spontaneous sorting task involving 44 local species of fish, 15 Menominee and 15 European American experts showed overall consensus (ratio of first eigenvalue $=7.6$ to $1,57 \%$ of variance accounted for, average first factor score $=.75$ ) but also reliable group differences. An analysis of variance on residual agreement (Nakao and Romney, 1984) revealed greater within- than between-group agreement and a significant population by within- versus between-group interaction. The form of this interaction is that only the Menominee informants displayed reliably greater withinthan across-group residual agreement. In short, it appears that the Menominee and European American informants share a common cultural model of fish but that the Menominee, in addition, share a somewhat distinct conceptual organization of fish.

Additional analyses indicate that the Menominee consensus contains an ecological component absent in the sorting of European American experts. Multidimensional scaling (MDS) yielded a dimension for Menominee experts that correlates with fish habitat. In addition, Menominee experts were reliably more likely than European American experts to mention habitat in their explanations for the sorts they created.

There are good reasons to think that these differences will generalize beyond expert fishermen. In a related line of work we asked our participants to nominate other people who fished a great deal but who would probably be less expert (Medin et al., 2002). We then interviewed these nominees and gave them the same sorting task. The first result is that our nonexperts were indeed less familiar with the 44 species of fish, indicating that our informants have a good sense of individual levels of expertise. The second result is that the less expert Menominee fishermen also tended to sort ecologically and to provide ecological justifications. For the European American sample we did find a reliable difference in sorting associated with expertise-less expert fishermen were more likely to sort in terms of goals and less likely to sort taxonomically than more expert fishermen. This pattern is consistent with less formal observations. For example, several European American fish experts told stories about how they were focused on getting the most and biggest fish when they were younger and that now they focused more on fishing as an experience to be enjoyed regardless of the number or size of fish caught.

The cultural difference in ecological orientation reflects preferences for organizing categories rather than knowledge 
differences per se. In another study we specifically asked Menominee and European American fish experts to sort fish by habitat. In this case we observed a strong overall consensus and no group differences.

\section{Ecological Relations}

A subset of 21 fish species was selected to probe directly for ecological relations. We presented all possible pairs (210) to 15 European American and 15 Menominee fish experts with a question: "Does fish A affect fish B and/ or does B affect A?" If the answer was yes, the expert was asked elaborate on the relation. Again we find an across-group consensus (ratio of first to second eigenval$\mathrm{ue}=4.2: 1,30 \%$ of variance accounted for, average first factor score $=.52$ ), coupled with reliable between-group differences (Medin et al., 2002). For relations reported by $70 \%$ or more of informants from either group we find: $85 \%$ reported by both groups, $14 \%$ by Menominee but not European American experts, $1 \%$ by European American fishermen but not Menominee fishermen. Content analysis reveals Menominee experts answer in terms of the entire life cycle of fish (e.g., spawn, fry, fingerlings, adults); European American experts generally answer in terms of adult fish. These results suggest that European American experts organize their knowledge around goals that target adult fish.

Again, we hypothesized that these were not differences in knowledge but rather knowledge organization. In a follow-up study ( $n=14$ per group) we again asked about fish-fish interactions, but reduced the number of pairs from 210 to 34 and ran the task at a slower pace ( $30 \mathrm{~s}$ per pair rather than about $10 \mathrm{~s}$ per pair). If European American experts have the same knowledge base but not necessarily one organized around ecological relations, then the group differences should disappear. They did. Using the relations reported for these 34 pairs on the longer task as a base, we found that European American experts now report reliably more relations (means of 29.3 versus 17.3), including more relations involving spawn and more reciprocal relations. Menominee experts showed no reliable changes across tasks, and the $64 \%$ advantage noted for Menominee fishermen on the longer task was reduced to a nonsignificant $11 \%$. This suggests that the cultural differences are in "habits of mind" or knowledge organization, rather than knowledge per se.

\section{Summary}

Our previous work shows that Menominee fishermen tend to take an ecological orientation to conceptualizing fish. They also commonly express the attitude that every fish has a role to play, and are less likely than European American fishermen to think of fish in terms of positive (game fish) or negative ("garbage fish") utility. In the study to be reported here we examine values and attitudes towards various fishing practices more directly. Although both groups report wanting to save fish as a resource, the goal of conservation is supported by different strategies in the two groups. As we noted before, Menominees are guided by a "do not waste" ethic. European American fishermen, in contrast, tend to focus on catch and release as a conservation strategy.

These group differences might be best described as different orientations with European American experts being more goal oriented and Menominee more ecologically oriented. Although both groups presumably share the goal of preserving fish as a resource, we wondered how the differences in orientation might be reflected in values and attitudes toward different fishing practices. A key focus, the subject of Experiment 2, is on how each group perceived the other.

\section{Experiment 1: Values, Attitudes, and Practice}

Study Area and Research Populations

The research area consists of the Menominee Reservation and adjacent Shawano County, just south of the Reservation, central Wisconsin. Participants were locally recognized experts (15 Menominee and 17 European American), nominated by their peers (for each community). Expertise was further verified through a test of familiarity with local fish species, necessary in order to not conflate culture and expertise.

The two groups did not differ in years of experience fishing (median=40 years) or age (average 44.8 for European Americans and 48.8 for Menominee). They were drawn from the pool of experts who participated in the (Medin et al., 2002; Medin et al., in press) studies and there was considerable overlap of participants across studies. Given that our probes concerned values and practices, it is important to note that this interview was typically the seventh or eighth interview we had done and that we often saw participants outside of this more formal context. ${ }^{3}$

Median family income is higher in Shawano County $(\$ 38,000)$ than on the Reservation $(\$ 27,000)$ (Bureau of the Census, 1999). The average household size is also substantially higher on the reservation than off ( 3.75 vs. 2.50$)$. All participants show a strong interest in fishing and spend a substantial amount of time engaged in fishing or activities related to it. Informants were paid for their participation.

\footnotetext{
${ }^{3}$ One index of rapport is that our experts did not hesitate to admit that they had engaged in practices that are illegal.
} 
Table I Items for Probing Fishing Attitudes Towards Various Fishing Practices

1. Doing catch-and-release only

2. Spearfishing suckers and/or carp

3. Spearfishing walleye or northern

4. Having a trophy fish mounted by a taxidermist

5. Fishing for bluegill or sunfish for food

6. Fishing for northern or muskie for food

7. Fishing for largemouth or smallmouth bass for food

8. Using setpoles to catch trout

9. Selling a fish

10. Keeping undersized fish

11. Participating in fishing contests

12. Fishing on spawning beds

13. Pretending to fish for suckers hoping to get a sturgeon on the line

14. Culling out smaller fish to get the largest possible limit

15. Using fish finders

16. Someone taking more than their limit in order to feed their family 17. Someone giving away all of the fish they catch

\section{Materials and Procedure}

In a first task we asked individuals to rank order 15 species according to the importance each fish has for the individual: sturgeon (Acipenser fulvescens), black sucker (Catastomus commersonnii), yellow bullhead (Ameiurus natalis), bluegill (Lepomis macrochirus), brook trout (Salvelinus fontinalis), brown trout (Salmo trutta), gar (Lepis osteus), bluntnose minnow (Pimephales notatus), muskellunge (Esox masquinongy), largemouth bass (Micropterus salmoides), smallmouth bass (Micropterus dolomieu), northern pike (Esox lucius), river shiner (Notropis blennius), walleye (Stizostedion vitreum), perch (Perca flavescens). Fish species were represented on name cards and individuals were asked to arrange these cards in order of descending importance.

Table II Average Species Rankings by Menominee and European American Fish Experts

Note: Lower numbers indicate higher value.
In a second task we asked our experts to rank order a set of six goals for fishing, drawn from previous interviews and the literature: (1) Fishing as a way of being close to nature, (2) Fishing as a challenge to outsmart the fish, (3) Fishing as a food source, (4) Fishing to get a trophy-sized fish, (5) Fishing for relaxation, and (6) Fishing as an activity to pass on to future generations. If an expert indicated that he could not rank order the goals, he was asked to rate them on a seven point scale with one representing not a goal at all and seven representing a very important goal. We later converted these ratings into rank orderings.

For the third and final task experts were asked to rate 17 different fishing practices on a seven-point scale where one represents strong personal disapproval, four a neutral attitude and seven strong approval (see Table I). These practices emerged from previous interviews.

The three rating tasks took about $30 \mathrm{~min}$ to an hour to complete. Often the participants explained the basis or justifications for their ratings or simply told a story about various values or practices.

\section{Results}

\section{Rank Ordering of Species}

The consensus rankings of the 15 species of fish are summarized in Table II. Lower numbers correspond to higher rankings. Somewhat to our surprise we found a strong cross-group consensus (ratio 1st/2nd factor eigenvalue: 7.2 ; first factor explains $63 \%$ of the variance, all first factor scores positive and high, average: 0.76). Nonetheless the overall consensus was coupled with reliable group differences (expressed in significant differences with respect to the second factor loadings $(F=22.9$; Mse=1.2; $p=0.000)$ ). These differences indicate the existence of clear

\begin{tabular}{llll} 
Table II Average Species & & Menominee & European American \\
\cline { 2 - 4 } Rankings by Menominee and & Species & & 8.6 \\
Experts & Sturgeon & 9.1 & 12.1 \\
& Black sucker & 12.0 & 10.0 \\
& Yellow bullhead & 11.1 & 4.8 \\
& Bluegill & 5.4 & 6.8 \\
& Brook trout & 2.2 & 7.9 \\
& Brown trout & 2.6 & 13.7 \\
& Gar & 14.5 & 12.0 \\
& Bluntnose minnow & 13.0 & 5.4 \\
& Muskie & 8.7 & 6.4 \\
& LM bass & 4.4 & 6.5 \\
SM bass & 7.3 & 5.5 \\
Note: Lower numbers indicate & Perch & 6.5 & 11.0 \\
higher value. & Walleye & 11.9 & 2.9 \\
& & 4.6 & 5.9
\end{tabular}


Table III Goal Rankings

\begin{tabular}{|c|c|c|c|c|c|c|}
\hline \multirow{2}{*}{$\begin{array}{l}\text { Raters } \\
\text { Rated }\end{array}$} & \multicolumn{3}{|c|}{ European American } & \multicolumn{3}{|c|}{ Menominee } \\
\hline & Self & Euro-Am. & Menom. & Self & Menom. & Euro-Am. \\
\hline A. Being close to nature & 2.4 & 3.2 & 4.6 & 3.0 & 3.0 & 3.2 \\
\hline B. For the challenge to outsmart the fish & 3.4 & 3.7 & 3.3 & 4.4 & 4.6 & 3.7 \\
\hline C. As a source of food & 4.6 & 3.9 & 3.7 & 2.7 & 1.7 & 2.5 \\
\hline D. To catch a "trophy fish" & 4.6 & 3.9 & 1.9 & 5.0 & 5.4 & 4.5 \\
\hline E. As a way to relax & 2.6 & 2.4 & 2.6 & 2.4 & 3.1 & 3.5 \\
\hline F. As an activity to pass on to future generations & 2.9 & 2.9 & 4.2 & 3.2 & 3.3 & 3.5 \\
\hline
\end{tabular}

The column labeled 'Self' gives the average of the individual ratings in Experiment 1 broken down by group (first and fourth column).

submodels that separate the two groups. Looking at the actual rank ordering we find the biggest differences with respect to brook and brown trout (average ranking for Menominee: 2.2 and 2.6; average ranking for the European American experts: 6.8 and 7.9; the differences for both fish are highly significant: $F=21.6$; Mse $=164 ; p=$ $0.000)$ as well as with respect to the muskie and walleye (average ranking for European Americans: 5.4 and 2.9; average ranking for the Menominee: 8.7 and 4.6; only the difference for muskie is significant: $F=8.2$; $\mathrm{Mse}=86$; $p=0.007)$. Although both groups value all of these fish, Menominee assign a higher value to the two trout species, and European Americans preferentially value muskie and walleye. These modest differences should not distract us from the wider consensus that exists between the two groups. For example, the six fish ranked lowest are not only the same for both groups but are even placed in exactly the same order. The overall correlation of rankings was +.81 .

\section{Goal Rankings}

The average rankings for the six goals are summarized in the first and fourth columns of Table III. Lower numbers correspond to more important goals. Given that each goal had been endorsed by several experts in earlier interviews, we had no strong reason to expect consensus either within or across groups or even a clear ranking of goals. Indeed, we did not find consensus across groups or for either of the two groups individually. (Only the European American experts approached a consensus.) This is an important finding, indicating the diversity of goals among members of both groups.

Table IV Reported and Anticipated Rating of Different Practices

\begin{tabular}{|c|c|c|c|c|c|c|}
\hline \multirow{2}{*}{$\begin{array}{l}\text { Raters } \\
\text { Rated }\end{array}$} & \multicolumn{3}{|c|}{ Euro-American } & \multicolumn{3}{|c|}{ Menominee } \\
\hline & Self & Euro-Am. & Menom. & Self & Menom. & Euro-Am. \\
\hline Catch \& release only & 4.5 & 3.1 & 4.3 & 4.7 & 3.3 & 3.1 \\
\hline Spearfish suckers/carp & 5.9 & 5.9 & 3.4 & 5.1 & 5.0 & 6.2 \\
\hline Spearfish walleye/no & 1.0 & 1.1 & 1.2 & 4.0 & 5.4 & 5.9 \\
\hline Trophy mounted & 4.4 & 4.8 & 6.7 & 4.9 & 3.9 & 4.6 \\
\hline Bluegill/sunfish food & 6.0 & 6.4 & 6.2 & 6.9 & 7.0 & 6.5 \\
\hline Northern/muskie food & 2.9 & 3.2 & 5.6 & 6.1 & 6.8 & 5.7 \\
\hline LM/SM bass food & 3.4 & 3.8 & 5.5 & 6.5 & 6.8 & 5.7 \\
\hline Setpoles for trout & 2.5 & 2.6 & 1.1 & 3.3 & 3.3 & 6.1 \\
\hline Selling fish & 2.0 & 1.7 & 1.7 & 1.3 & 1.5 & 4.4 \\
\hline Keep undersized fish & 1.6 & 2.6 & 2.2 & 2.3 & 2.4 & 4.8 \\
\hline Fishing contests & 4.9 & 4.9 & 6.7 & 4.3 & 5.0 & 4.4 \\
\hline Fishing spawning beds & 3.0 & 4.2 & 4.0 & 2.8 & 4.3 & 5.9 \\
\hline Suckers for sturgeon & 3.6 & 3.8 & 3.0 & 2.1 & 2.9 & 5.7 \\
\hline Cull for biggest limit & 2.9 & 3.2 & 3.4 & 1.9 & 3.5 & 4.9 \\
\hline Using fish finders & 5.9 & 5.9 & 6.5 & 3.6 & 4.8 & 6.1 \\
\hline Exceed limit for family & 2.9 & 4.1 & 2.8 & 5.2 & 5.3 & 6.0 \\
\hline Giving all fish away & 3.9 & 3.3 & 3.2 & 4.8 & 5.1 & 4.8 \\
\hline
\end{tabular}

'Self' is the average individual rating in Experiment 1. 
Notably, the three most important goals for European American fish experts were being close to nature, relaxing, and passing fishing down to future generations. Going for a trophy-sized fish was tied with fishing as a source of food as the least important goal. Since our data are in the form of rankings we cannot draw conclusions about the absolute importance of any of these goals. For Menominee fish experts the most important goals were fishing for food and as a way to relax; the least important goal was going for a trophy-sized fish (indeed several experts went out of their way to say that it was not a goal at all).

Despite the lack of consensus, we were nonetheless able to detect group differences on specific goals. Menominee experts give significantly higher importance to "fishing for food" $(F=11.8 ; \mathrm{Mse}=26 ; p=0.002)$, while European American experts tend to place higher value on "fishing as a challenge to outsmart the fish (marginally significant: $F=3.6$; Mse $=7.5 ; p=0.06$ ). These data are in line with the observation that European American fishermen tend to see fishing as a contest or sport, but, again the overall picture of European American goals is a far cry from the stereotype of sportsmen being fixated on trophy fish. For both groups trout and walleye are mostly caught for food (though European American fishermen may release large walleye). Muskie, the most prized fish for many fishermen, is a sport fish that is typically not eaten by European American fish experts.

\section{Ratings of Practices}

We expected to observe a number of differences in ratings of practices related to both specific goals and historical practices. For example, for centuries the Menominee have speared fish in the spring when they are spawning as an efficient means of food gathering. Obviously, spearing is self-defeating with respect to catch and release. Consequently, it would have been surprising if there were no group differences in rating practices like spearfishing (columns 1 and 4, Table IV). We found modest overall consensus (ratio of first to second eigenvalue $=2.6$, first factor $=44 \%$ of variance, mean first factor $=.63$ ) and reliable group differences. The main group differences are as follows. Menominee experts gave higher ratings to catching bass, northerns, and muskie for food (strong approval versus neutral), higher ratings to someone taking more than the limit to feed their family (modest approval versus modest disapproval) and higher ratings to spearfishing walleye (neutral versus strong disapproval). The Menominee fishermen were sharply divided on spearfishing walleye and the average reflects an equal mixture of strongly positive and strongly negative ratings. Menominees opposed to it say that females are being speared and their spawn wasted. Menominees in favor of spearing say that they only spear the males. (Data to be reviewed later on Ojibwe spearfishing suggests that about ten males are speared for every female walleye speared.)

European American fishermen gave higher ratings to using fish finders (strong approval versus neutral) and to pretending to fish for suckers hoping to get a sturgeon (neutral versus strong disapproval). It is illegal to fish for sturgeon with hook and line; some fishermen engage in this practice in the spring when sturgeon come up river to spawn. Historically, sturgeon have been sacred for the Menominee (Beck, 1995) so this difference in values is not surprising.

\section{Discussion}

The results form a coherent pattern. The Menominee experts place a higher priority on fishing for food and European American fishermen are more inclined to view fishing as a challenge. These differences in goals are reflected in differences in attitudes towards specific practices such as spearfishing or targeting bass, northerns, and muskies for food. One surprising result was that European American fishermen endorsed using fish finders, which, on the surface, doesn't appear to be sporting. A common comment was that it is one thing to find fish and quite another to catch them (some experts said that they only used fish finders to map out the terrain, e.g., dropoffs). Another surprising result was the wide diversity of Menominee attitudes towards spearfishing. This finding figures into the rationale for Experiment 2.

Before shifting to the second experiment, it is important to note the broad commonalities across groups. For example, the rank ordering of species was highly correlated across groups. Menominee rank trout somewhat higher, perhaps reflecting their food orientation but also reflecting the presence of many rivers and streams on the reservation and the fact that one does not need a boat to fish for trout. Most important, however, are the similarities in attitudes towards various fishing practices. Both groups condemn selling fish, keeping undersize fish, fishing on spawning beds, using setpoles to catch trout, and culling our smaller fish to get the largest possible limit. The key question in Experiment 2 is to what extent these groups are aware of their modest differences and their substantial shared values.

\section{Experiment 2. Intra- and Intergroup Perception}

Experiment 2 addresses the question of the relationship between the actual similarities and differences noted in Experiment 1 and perceived within- and between-group similarities and differences. In this task we asked the same 
Table V Projected Fish Value Rankings for Own and Other Group

\begin{tabular}{|c|c|c|c|c|}
\hline \multirow{2}{*}{$\begin{array}{l}\text { Raters } \\
\text { Rated }\end{array}$} & \multicolumn{2}{|l|}{ Menominee } & \multicolumn{2}{|c|}{ European American } \\
\hline & Menominee & Euro-Am. & Menominee & Euro-Am. \\
\hline \multicolumn{5}{|l|}{ Fish } \\
\hline Sturgeon & 9.6 & 8.7 & 5.4 & 10.9 \\
\hline Black sucker & 11.9 & 11.7 & 11.5 & 11.9 \\
\hline Yellow bullhead & 10.9 & 10.3 & 10.6 & 10.0 \\
\hline Bluegill & 4.7 & 6.7 & 6.1 & 4.0 \\
\hline Brook trout & 1.6 & 5.5 & 2.4 & 5.1 \\
\hline Brown trout & 2.3 & 5.6 & 3.1 & 7.1 \\
\hline Gar & 14.4 & 13.9 & 13.9 & 14.1 \\
\hline Bluntnose minnow & 13.4 & 13.4 & 12.2 & 13.2 \\
\hline Largemouth bass & 4.2 & 2.8 & 6.8 & 4.3 \\
\hline Smallmouth bass & 7.5 & 7.3 & 7.5 & 7.2 \\
\hline Northern & 6.0 & 5.5 & 6.2 & 5.4 \\
\hline River shiner & 12.4 & 12.9 & 12.6 & 12.5 \\
\hline Walleye & 4.3 & 1.4 & 4.8 & 2.1 \\
\hline Perch & 7.5 & 7.8 & 6.2 & 6.2 \\
\hline Muskie & 8.6 & 4.6 & 7.9 & 5.9 \\
\hline
\end{tabular}

questions as before. However, rather than exploring each individual's goals and values (to be aggregated statistically to group models) we asked each informant how they thought equally expert members of their community or the other community might answer the probes concerning values, goals, and attitudes.

There is good evidence that people perceive both other groups and their own reference group as more extreme than it objectively is. For example, Prentice and Miller (1993) found that college students systematically overestimated the amount and perceived desirability of alcohol consumption among other students and that, at least for male students, this misperception led to an increase in drinking. In other words misperception of a group norm can cause a self-fulfilling feedback to make the perceived group norm even more extreme. This has implications for negotiation and conflict resolution (see Ross and Stillinger, 1991; Thompson and Gonzalez, 1997, for an analysis). There is other evidence that people tend to believe that their behavior speaks for itself, that they see the world objectively, and that only other people are susceptible to bias and misconstrual of events. This raises the possibility that members of one group will feel no need to try to take the perspective of members of the other group in understanding intentions, values, and behaviors. If you see the world objectively and someone does something transparently inappropriate (e.g., keeping a largemouth bass), then the conclusion that their motives are bad may be so automatic that it comes to you as a fact, not an inference. To the extent that this tendency is common it creates greater opportunities for intergroup misperception.

\section{Participants}

The informants were 14 European American and 14 Menominee fishing experts, virtually all of whom participated in Experiment 1. The average age, education, and years fishing did not differ from each other or from Experiment 1. Informants were paid for their participation.

\section{Materials and Procedure}

The rank ordering and ranking tasks were exactly the same as used in Experiment 1. The only difference was that each participant was asked to answer each of the probes twice. For the first iteration informants were asked to answer the questions the way they thought the typical fisherman from their community, equally expert, would answer them. We added that in many cases that the answers would probably be the same as they themselves would give but that sometimes people recognize that their preferences and values might not agree with a typical expert's answers. After the species ranking, goal ranking, and practices rating task was completed, informants were asked to repeat the task, this time answering from the perspective of an equally expert fisherman from the other community. After these tasks were completed we showed participants the mean ratings for each group from Experiment 1.

\section{Results and Discussion}

The results were striking and largely unanticipated. We had expected that European American experts would be 
surprised that Menominee experts are divided on the question of spearing walleye and that Menominee experts might think that European American fishermen are more sports and trophy oriented than they actually are. But we were not prepared for just how strongly perceived group differences would depart from actual differences.

Perception of Relative Importance of Fish

We asked informants to rank order the importance of 15 species of fish for (1) members of their own group, and (2) members of the other group. The results show striking accuracy. The main data appear in Table V. Each number represents the average ranking, so smaller numbers correspond to more highly valued fish. For example, Menominee experts gave highest rankings to brook trout and brown trout. Note also that both Menominee and European American informants correctly thought that trout were more important for Menominee than European American fishermen. Both groups also predicted that European American fishermen would rank walleye and muskie very highly (and more highly than the Menominees) and that also was the case. The only instance of what one might call misperception arose for the bluegill. Although the effect is not large, each group thought its own group would value the bluegill more than the other group.

Overall, each group very accurately anticipates the rankings that members of the other group would give. The two groups generally agree on their rankings (the crossgroup correlation was +.87 ) but this accuracy extends well beyond general agreement. Menominee estimates of European American values correlate +.95 with European American values and European American estimates of Menominee values correlate +.93 with Menominee values.

\section{Goal Rankings}

The predicted rankings for the two groups are summarized in Table III. Again, smaller numbers refers to higher priorities. Columns two and five give predictions for one's own group and columns three and six give the predictions by the other group. Each group was fairly accurate at anticipating the goals of members of their own group. Menominee experts thought that European American experts would be much more focused on catching a trophy-size fish than they actually are. Menominee fishermen also underestimated the importance for European American experts of fishing as an activity to pass down to future generations and for being close to nature. The largest discrepancy for European American predictions is the underestimation of the importance to Menominee experts of fishing as a way to relax.
Values and Attitudes Concerning Practices

Predictions for own group and the other group are summarized in Table IV. Columns two and five give predictions for one's own group and columns three and six give the predictions by the other group. Menominee experts think that European American fishermen would be more approving of fishing contests and getting a trophy fish mounted than European American experts report, and European American experts think Menominee experts would approve selling fish, keeping undersized fish, fishing on spawning beds, culling smaller fish to get the biggest sized limit, and using setpoles to catch trout. As we noted before, such practices are disapproved of by both groups. European Americans even believe that Menominee would approve fishing for suckers hoping to get a sturgeon on the line.

For both European American and Menominee experts we find strong consensus with respect to each group's perception of their own group (in-group) and the other group (out-group) responses (For European Americans: 1st/ 2nd factor eigenvalue: 4.7 ; variance explained: $60.1 \%$ aver. 1 st factor score: 0.76 ; Menominee: $1 \mathrm{st} / 2$ nd factor eigenvalue: 9.26; variance explained: $65.8 \%$ aver. 1 st fact. score: 0.80 ). This indicates that each group entertains a clear model of both in-group and out-group performance. Obviously, these perceptions do not necessarily reflect the actual models held by each group.

A cross-group consensus analysis was conducted to see how well the two groups agree in their perceptions. That is, do European American and Menominee experts (1) have the same beliefs about European American values and attitudes, and (2) have the same beliefs about Menominee values and attitudes? This cross-group analysis reveals consensus for both European American and Menominee experts only with respect predictions for the European American responses (eigenvalue $=9.3$ to $1,66 \%$ of variance accounted for by the first factor, and average first factor score $=.80$ ). In light of the individual group consensus this suggests that the Menominee model of European American experts is in basic agreement with European American experts' perceptions of their own values and behaviors. This basic cross-group consensus is coupled with significant residual group differences, as members of both groups differ significantly on their second factor scores. In other words the general overall agreement is coupled with more specific systematic differences in perceptions.

Corresponding cross-group analyses with respect to the Menominee response pattern fail to show consensus. This underscores an asymmetry with respect to cross-group perception. In short, European American models of Menominee are strikingly different from Menominee individual responses and Menominee predictions for the group consensus. Overall, these data indicate that 
European American fishermen hold strong, incorrect expectations concerning Menominee values.

Where do these misperceptions come from? Given that we had not anticipated just how large the discrepancy would be, this question is largely outside the scope of our present inquiries. Nonetheless, we will offer some suggestions and provide some additional correlational analyses that may bear on them. We believe that the source for these misperceptions comes from differences in specific goals and knowledge organization, reinforced by patterns of media coverage. Differences in specific goals can lead to rejection of another group's values and practices.

Our sample is not large enough to make conclusive observations that link subgroups of European American experts to stereotyping. However, in a first attempt to understand the relation of knowledge structure and stereotyping we searched within group differences in task one (categorization of fish) for patterns in stereotyping. We expected that European American individuals sharing a basic knowledge organization with Menominee experts might show fewer stereotypes about Menominee values and behavior. There are three reasons to make this prediction: (1) Both results might be driven by social network proximity - a better understanding of Menominee knowledge organization may go with a better appreciation of their values and attitudes. (2) A knowledge organization similar to the Menominee might allow a better appreciation of values and attitudes Menominee hold. (3) The more that a European American expert's knowledge is strongly organized around goals, the less they may understand Menominee values.

If our hypothesis is correct we should find a positive correlation between European American experts' use of a "garbage fish category" and the stereotyping of Menominee values and attitudes. Similarly, we should find a negative correlation between their use of ecological reasoning and stereotyping. Stereotyping was calculated as the difference between the Menominee self-reported data and a European American expert's estimate of Menominee responses on (1) spearfishing walleye, (2) using setpoles, (3) selling fish, and (4) fishing for suckers hoping to get a sturgeon on the line.

Nonetheless, we find a positive correlation between stereotyping and mentioning sport fish as a category $(r=$ 0.43 ), and a clear negative correlation between the use of ecological justifications and stereotyping $(r=-0.45)$. These suggestive data fall short of statistical reliability. The ranking data are more clear cut. We find that the higher the ranking of the "big five" sport fish (Northern, muskie, walleye, largemouth bass, smallmouth bass), the greater the stereotyping $(r=+0.62$ for individual rankings and a reliable +0.50 for predictions for other majority culture fishermen).
In a second exploratory analysis we examined relationships between the fish ranking task and stereotyping. There is a discrepancy between perception and actuality that we have deferred addressing until now. The European American fish experts thought that the Menominee experts would rank the sturgeon more highly than they actually do. As we noted earlier, the Shawano dams on the Wolf River prevent sturgeon from reaching the reservation itself. Many European American fishermen may be aware of Menominee efforts to get ladders installed on these dams so that sturgeon could return to the reservation for spawning. Some may also know that sturgeon are considered sacred so it is not surprising that European American experts thought that Menominee experts would value sturgeon highly. Indeed, we ourselves were initially surprised that our Menominee experts did not rank sturgeon more highly. The responses of the Menominee experts tend to be more pragmatic. A typical comment was "we don't have them on the reservation any more." One expert who is an elder did not rank sturgeon highly because he thinks the meat is too rich.

The overall mean rank of 5.4 for the European Americans' expectations about Menominee ranking conceals a great deal of variability, and we decided to investigate further. Specifically, we looked how answers to the values probe "pretending to fish for suckers hoping to get a sturgeon on the line" correlated with beliefs about Menominees valuing sturgeon more than white fishermen. Recall that Menominees disapprove of this practice but that expert European American fishermen as a group thought that Menominees would approve of it more than their own group does. For each European American expert we computed two scores: (1) rating for Menominee approval of pretending to fish for suckers minus the same anticipated rating for European American fishermen, and (2) anticipated Menominee ranking of sturgeon versus expected ranking for European American experts. We then correlated these two scores across our European American experts.

One hypothesis is that experts who knew enough about Menominee culture to know that they value sturgeon would be less likely to think that Menominee would approve of trying to get sturgeon on their lines for entertainment. If that were the case then we should observe a negative correlation between the two scores. The observed correlation was +0.70 , highly significant and in the opposite direction! Those that thought Menominee experts would value sturgeon also thought that they would approve of getting sturgeon on the line for entertainment. Another way of describing the results is that the European American experts who know enough about Menominee fishing values to anticipate that they would NOT rank sturgeon highly were also those experts who judge that Menominee would NOT approve of pretending to fish for suckers hoping to have a chance to wrestle with a sturgeon. 
We also looked at the correlation between thinking that Menominees would rank sturgeon high and a combined measure of values and practices associated with stereotyping: (1) selling fish, (2) keeping undersized fish, (3) culling out smaller fish to get the largest bag limit, (4) fishing on spawning beds, (5) using setpoles to catch trout, and (6) pretending to fish for suckers hoping to get a sturgeon on the line. Again for each European American expert we took the difference between anticipated approval by Menominee versus European American experts as our index of stereotyping. The correlation between this index and thinking that Menominee experts would rank sturgeon comparatively higher was +0.65 , which is statistically significant. So the correlation holds not only for the item concerning suckers and sturgeon but also for stereotyping as a whole.

Overall, these observations suggest that knowing a bit about Menominee values in the abstract was not enough to undermine stereotyping but knowing Menominee fishermen's specific values was. Of course, it could be that the judgment that Menominee fishing experts would not value the sturgeon more highly than European Amercian fishermen was based on lack of knowledge rather than a specific belief. To address this question, we did a final correlation analysis.

Recall that European American experts as a group knew that Menominee place greater relative value on trout. In our final analysis we looked at the correlation between predicting that Menominee would value sturgeon relatively more and knowing that Menominee value trout relatively more. The correlation was significant and negative $(-0.62)$, In other words, the European American experts who correctly thought that Menominee value trout tended to think correctly that Menominee would not preferentially value sturgeon. But the more important data concern stereotyping. Using the six items mentioned previously to get an overall measure of stereotyping, we find a reliable negative correlation $(-0.49)$ between knowing that Menominee preferentially value trout and stereotyping. The better the European American experts knew Menominee rankings, the less stereotyping they displayed. We are currently gathering social network data as a converging source of evidence. Data collected so far are consistent with the idea that knowing specific Menominee who fish is negatively correlated with stereotyping.

We should also bear in mind that our observed asymmetry in accuracy of cross-group perceptions may be associated with the asymmetry of cross-group experiences. Specifically, it is more common for Menominees to conduct business off the reservation than for European Americans to do so on the reservation. ${ }^{4}$ This could also lead to more opportunities for Menominees to observe European Amer-

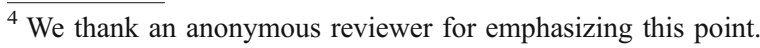

ican fishermen than vice versa. ${ }^{5}$ The social network data we are collecting should bear on the asymmetry hypothesis.

\section{General Discussion}

The most striking finding is that the very modest actual differences in goals, values, and attitudes are accompanied by massive perceived differences. Furthermore, the effect is strongly asymmetrical. Menominee fish expert judgment modestly exaggerated the sportsman's model of fishing but European American fish expert judgments of Menominee values are wildly discrepant from stated Menominee values. One explanation that can readily be rejected is that the Menominee stated values do not correspond to actual behaviors. As we noted earlier, however, recent surveys of fish populations in lakes and rivers on the Menominee reservation show that fish populations are healthy and abundant (Schmidt, 1995). In short, the Menominee tribe has done a good job of managing fish as a reservation resource.

We suggest that these misperceptions are mediated by differences in specific goals and associated knowledge organization, reinforced by patterns of media coverage (for related analysis of effects of media coverage see Gilens, 1996; Gilliam and Iyenger, 2000). In the remainder of this paper we briefly consider the modest stereotyping of European American fishermen by Menominees and then turn to the much larger stereotyping by European American fishermen.

The sportsman's model of searching for trophy-sized fish is common in the media. It is easy to get the idea that getting a trophy fish is the be all and end all of fishing. Fishing contests on cable television only reinforce this impression. Sporting magazines are full of photographs of particularly large game fish that anglers have caught. Rarely does an article mention someone catching two 16inch walleye and making a nice meal from them (and there certainly would be no photo). It is also important to note that although the Menominee as a whole tended to have stereotypes about European American fishermen, there were a number of exceptions - these are group trends that do not hold for every individual.

If the gap between prediction and reality is large for Menominee predicting European American values, then it is enormous for European American fishermen predicting Menominee values. The fact that they thought that Menominee would be more approving of spearfishing walleye than they are is not so surprising. But they also thought, contrary to fact, that Menominee fishermen would strongly approve of virtually every practice that both groups condemn.

\footnotetext{
${ }^{5}$ One might think that the situation is more symmetrical when both European American and Menominee fishermen are fishing off the reservation, but since state regulations apply to both groups in this context this still leaves room for speculation about how Menominees fish when they are on the reservation.
} 
Differences in specific goals can lead to rejection of another group's values and practices. For example, Menominee fishermen uniformly endorse eating largemouth and smallmouth bass, a practice that many European American fishermen reject because "they are such good fighters that one should only do catch and release." Fishing for sport is institutionally sanctioned and encouraged. For example, the ethic of catch and release (Hummel, 1994) is reinforced by Wisconsin Department of Natural Resources (WDNR) policy. In parts of Wisconsin the WDNR fishing regulations include a "catch and release only" season for largemouth and smallmouth bass in the spring when bass are spawning (Wisconsin Department of Natural Resources, 2002). In 2005 the state legislature mandated that the WDNR approve the normally illegal practice of culling fish for a number of bass tournaments.

Media coverage of the controversy surrounding Native American spearfishing exacerbates the effects of these differing orientations, especially when these rights cover off-reservation waters. When we revealed the Menominee ratings to European American fishermen, a common response to the mismatch was, "You know, I think I was answering the way that the Chippewa might answer." (Another common response was "Well, I know Menominee really take care of their forest, so it makes sense that they also take care of their fish.")

The Chippewa (or Ojibwe) have received the greatest publicity as the only tribe with off-reservation fishing rights (in the territories they ceded in the nineteenth century, which cover much of northern Wisconsin). In these waters, the daily limit on walleye is lower than in the rest of Wisconsin and it is a natural inference that spearfishing of walleye in the spring when they are spawning depletes the resource. A decade ago Ojibwe spearfishing of walleye and the associated demonstrations and protests in the spring by organizations like Protect Americans Rights and Resources (PARR) attracted nightly attention. This attention seemed to have the goal of creating heat, not light. Moderate voices were rarely quoted and the television coverage focused on the fact of controversy, not on factual information that might be relevant to it.

These facts are as follows. Records over the past decade (Wisconsin Department of Natural Resources, 2000, 2002) indicate that sports fishermen harvest more than 12 walleye for every one taken by Ojibwe spearers. The Ojibwe also maintain fish hatcheries, strip the spawn from any females they spear and restock in the same waters where they spear (e.g., in 1998 Ojibwe stocked ceded territory waters with over 26 million walleye fry and more than 700,000 walleye fingerlings [Wisconsin Department of Natural Resources, 2002]). Despite these numbers, many sportsfishermen may balk at the image of spearers taking large female walleye. But WDNR monitoring also undermines this image. $^{6}$ Sexing of harvested fish during the 1985-1999 period shows that a breakdown of $83 \%$ males, $10 \%$ females and $7 \%$ of unknown sex. The average length of walleye taken has been $15.5 \mathrm{in}$. So the image that best fits is of a 15inch male walleye, not a 25 -inch female.

The WDNR may indirectly and perhaps inadvertently contribute to the perception that Ojibwe spearers are depleting the walleye population by its policies concerning limits. A 1998 study commission recommended that the statewide limit be set at three walleye (a review board overturned this policy). If the DNR is implementing this policy where it can, namely where lakes have been declared for spearing, then the result may be that Ojibwe fishermen take the blame for the lower limits.

Another source of misperceptions consists of anecdotes and stories, sometimes rooted in reality, often not. Lurid stories about tossing walleye in dumpsters are highly memorable and tempting to repeat, regardless of the authenticity of the source or the veracity of the information. In at least one case, a television station dispatched a TV crew to document this waste, only to discover that what appeared to be discarded walleye were actually the leavings of fish that had been cleaned-Ojibwe practice of leaving the head intact during filleting had fooled casual observation.

Returning to the mispredictions of Menominee values and practices, again it is important to note that the results reflect group patterns and in no way characterize every individual. A significant minority of the European American fishermen accurately predicted Menominee reported values. These tended to be men who had firsthand experience with Menominee fishermen and were familiar, for example, with the fact that Menominee preferentially value trout. Perhaps the best summary comes from one such fisherman who said, "I don't care if someone is NativeAmerican, African-American, Asian, or white, the vast majority will have good values and a few won't."

The generality of our results and the relative contributions of media coverage and mental models of nature to misperceptions is an open question. Nonetheless there is considerable reason to think that that our findings are not confined to fish experts and that mental models matter. In parallel research we have interviewed Menominee and European American hunters from the same study area in Wisconsin. Media coverage is much less of an issue with respect to hunting. ${ }^{7}$ Nonetheless we observe parallel and asymmetrical misperceptions of Menominee values and attitudes. European American hunters often say things like "Menominees kill all their deer. You can drive through the

\footnotetext{
${ }^{6}$ For 2003 walleye limits for lakes where Native Americans have offreservation spearfishing rights, see http://www.dnr.state.wi.us/org/ water/fhp/fish/ceded/walleye.htm

${ }^{7}$ There has been some controversy over tribes allowing hunters to shine deer, though the Menominee tribe has banned the practice.
} 
reservation and not see a single deer." This impression is inaccurate - surveys show that the deer population on the reservation is exactly in the midrange of estimates of the carrying capacity.

The cultural differences in ecological orientation also appear to be very robust. For example, we find parallel differences in Menominee and rural European American children on a reasoning task where both taxonomic and ecological strategies may come into play (Ross et al., 2003). In a further ongoing project, we have interviewed rural European American and rural Menominee parents and grandparents (Bang et al., 2005). One of our questions was "What are the five most important things for your children (or grandchildren) to learn about the biological world?" We then coded the responses into categories representing different perspectives on the natural world. Parents in general took a moral stance. For example, European American parents commonly said that they wanted their children to realize that they have a responsibility to take care of nature. In contrast, however, Menominee parents tended to talk about "Mother Earth" and wanting their children to understand that they are a part of nature. They were also more likely to mention continuity between the past and the future, mentioning both ancestors and coming generations. Note also that the term Mother Earth implies that it takes care of us rather than vice versa. It also embodies a relational view of nature, rather than seeing it as something external.

In conclusion, the most striking finding is the contrast between perception and reality: despite the strong overall consensus in knowledge, goals and values, European American fishermen see Menominee as vastly different. These results suggest that differences in how groups conceptualize nature may be critical to understanding intergroup conflict over resources.

\section{Supplemental Materials}

\section{S1. Individual Activity Ratings}

http://www.northwestern.edu/environment/ActivityRatings. htm

S2. Individual Cross-Group Ratings

http://www.northwestern.edu/environment/Rawdata.htm

S3. Averaged Cross-Group Ratings

http://www.northwestern.edu/environment/Tabledata.htm

\section{References}

Atran, S., Medin, D., Ross, N., Lynch, B., Coley, J., Ucan Ek', E., and Vapnarsky, V. (1999). Folkecology and Commons Management in the Maya Lowlands. Proceedings of the National Academy of Sciences 96: 7598-7603.

Atran, S., Medin, D., Lynch, E., Vapnarsky, V., Ucan Ek', E., Coley, J., Timura, C., and Baran, M. (2002). Folkecology, Cultural Epidemiology, and the Spirit of the Commons: A Garden Experiment in the Maya Lowlands, 1991-2001. Current Anthropology 43(3).

Bang, M., Townsend, J., Unsworth, S., and Medin, D. L. (2005). Cultural Models of Nature and their Relevance to Science Education. Paper presented at American Educational Research Association 2005 Conference, Montréal, Quebec, April 13, 2005.

Beck, D. R. M. (1995). The Importance of Sturgeon in Menominee Indian History. Wisconsin Magazine of History 79: 32-48.

Boster, J. S. (1987). Agreement between biological classification systems is not dependent on cultural transmission. American Anthropologist 89: 914-920.

Bureau of the Census (1999). United States Census 2000. Washington, DC: US Government Printing Office.

Chiarappa, M. J., and Szylvian, K. M. (2003). Fish for All. Michigan State University Press, East Lansing, Michigan.

Gilens, M. (1996). Race and poverty in America: Public misperceptions and the American news media. Public Opinion Quarterly 60: 513-535.

Gilliam, F. D., and Iyengar, S. (2000). Prime suspects: The influence of local television news on the viewing public. American Journal of Political Science 44: 560-573.

Graunke, G. (2003). American Rights Guardian Update (Protecting American Rights and Resources Newsletter) 5, 7. Available at www.parr1.com/ARGU7-5W2003.html.

Hall, P., and Pecore, M. (1995). Case study: Menominee tribal enterprises Madison, WI: Institute for Environmental Studies and the Land Tenure Center, University of Wisconsin-Madison.

Hummel, R. (1994). Hunting and Fishing for Sport: Commerce, Controversy, and Popular Culture. Bowling Green State University Press, Bowling Green, Kentucky.

López, A., Atran, S., Coley, J. D., Medin, D. L., and Smith, E. E. (1997). The tree of life: Universal and cultural features of folkbiological taxonomies and inductions. Cognitive Psychology 32: 251-295.

Medin, D., Ross, N., Atran, S., Burnett, R., and Blok, S. V. (2002). Categorization and reasoning in relation to culture and expertise. In Ross, B. (ed.), The Psychology of Learning and Motivation, vol. 41, Academic Press, New York, pp. 1-41.

Medin, D. L., Ross, N. O., Atran, S., Cox, D., Coley, J., Proffitt, J. B., et al. (2006). Folkbiology of freshwater fish. Cognition 99: 237-273.

Nakao, K., and Romney, A. K. (1984). A method for testing alternative theories: An example from English Kinship. American Anthropologies 86: 668-673.

Nesper, L. (2002). The Walleye War: The Struggle for Ojibwe Spearfishing and Treaty Rights. University of Nebraska Press, Lincoln, Nebraska.

"Petition Seeks to Separate Spearfishing, Gaming" Beloit Daily News 23 October (1997); available at www.beloitdailynews.com/1097/ 4wis23.htm.

Prentice, D. A., and Miller, D. T. (1993) Pluralistic Ignorance and Alcohol Use on Campus: Some Consequences of Misperceiving the Social Norm. Journal of Personality and Social Psychology 64: 243-256.

Radomski, P. J., and Goeman, T. J. (1995). The homogenizing of Minnesota lakefish assemblages. Fisheries 20: 20-23.

Romney, A. K., Weller, S. C., and Batchelder, W. H. (1986). Culture as Consensus: A Theory of Culture and Informant Accuracy. American Anthropologist 88: 318-338.

Ross, L., and Stillinger, C. (1991). Psychological barriers to conflict resolution. Negotiation Journal 7: 389-404.

Ross, N. (2002). Cognitive aspects of intergeneration change: Mental models, cultural change, and environmental behavior among the 
Lacandon Maya of southern Mexico. Human Organization 61:125-138.

Ross, N., Medin, D. L., Coley, J. D., and Atran, S. (2003). Cultural and experiental differences in the development of folkbiological induction. Cognitive 18: 25-47.

Schmidt, S. H. (1995). A survey of lakes on the Menonimee Reservation, Wisconsin. Master's thesis, University of Wisconsin, Stevens Point.

Thompson, L., and Gonzales, R. (1997). Environmental disputes: Competition for scarce resources and clashing of values. In M. Bazerman, D. Messick, A. Tenbrunsel, and K. Wade-Benzoni (eds.), Environmental, Ethics and Behavior: The Psychology of Environmental Evaluation and Degradation. San Francisco: New Lexington.
Tracy, L. (1998). State Trends. Council of State Governments Newsletter, Summer 1998; available at stars.csg.org/trends/ 1999/summer/su99st7.pdf.

"Tribal Claims Were Too Much," Milwaukee Journal Sentinel, 25, April (1999); available at www.jsonline.com/news/editorials/ apr99/0425tribal.asp.

Wisconsin Department of Natural Resources. (2000). Wisconsin's Lake Sturgeon Management Plan. Milwaukee, Wis.: Bureau of Fisheries Management and Habitat Protection.

Wisconsin Department of Natural Resources. (2002). "Open Water Spearing and Netting in Northern Wisconsin by Chippewa Indians During 2001." Great Lakes Indian Fish and Wildlife Commission Administrative Report. Wisc2002-01, Odanah, Wis.: Wisconsin Department of Natural Resources. 